$\xi=-1$

\title{
Optimization of flow forming process parameters of al-8014 using genetic algorithm
}

\author{
T Mahender $^{1 *}$, Bellam Venkatesh ${ }^{1}$ \\ ${ }^{I}$ Department of Mechanical Engineering, CMR Institute of Technology, Hyderabad, India \\ *Corresponding author E-mail: mahendert2015@gmail.com
}

\begin{abstract}
Flow forming is an advanced version of the metal spinning process in which the metal is formed into the desired shape without formation of a chip. There are many flow forming process parameters that will influence the surface roughness of the material. In the current study, three process parameters are considered in the flow forming of AA8014. The process parameters are speed of the mandrel, longitudinal feed and the flow rate of the coolant and the response is surface roughness. Design of experiments based response surface method (RSM) is used to study the effect of process parameters on the response. A quadratic mathematical model was developed by RSM is used for optimization of surface roughness by using an evolutionary technique Genetic Algorithm. The surface roughness obtained at optimum process parameters from Genetic Algorithm is in good agreement with the experimental results.
\end{abstract}

Keywords: Flow Forming; Surface Roughness; Optimization; RSM; Genetic Algorithm.

\section{Introduction}

Flow forming is one of the oldest methods of forming a chip less product, which is used to fabricate axisymmetric, thin walled seamless tubes etc. Flow forming process employs rollers, which apply a compressive force on the pre-formed tube, leading to the plastic deformation of the material in the radial and axial directions, results in an increase in length and decrease in thickness. Davidson et al. investigated on flow forming process parameters and stated that depth of cut has more contribution on the elongation of length than the rotational speed and feed [1]. M J Davidson et al. used Response Surface Method (RSM) optimization technique to optimize the surface roughness of flow forming of $\mathrm{Al}$ 6061 alloy. A quadratic mathematical model is also developed based on the process parameters to predict the surface roughness [2]. Rajiv Panda et al. studied the effect of a number of passes and intermittent annealing on reverse flow forming process. The tensile strength and the hardness of the pre-formed tube increases by increasing the number of passes and ductility increases by intermittent annealing after two passes [3]. G. Venkateshwarlu studied the effect of process parameters on the variation of the thickness of flow forming of Al 6061 tubes. [4]. M. Srinivasulu et al. studied the effect of process parameters on the flow forming of the AA6082 tube and concluded that the lower feed rate and speed of the mandrel at $150 \mathrm{rpm}$ improve the surface roughness [5]. Liu et al. simulated the flow forming using ABAQUS/Explicit software and concluded that simulation results are in good agreement with the experimental results [6]. Hamid R et al. studied the effect of mechanical properties of AA7075-O in the reduction of the thickness of flow forming process and stated that roughness, yield strength, tensile strength and hardness increases with reduction in thickness [7]. Flow forming process parameters were optimized by various researchers [12], [13] but a very less work has been carried out by an evolutionary technique Genetic Algorithm [8].
There are many process parameters which influence the responses of the product (i.e. reduction in thickness, elongation of length, surface roughness etc.). In the current study, the surface roughness is taken as the response of AA8014 alloy by considering the i) speed of the mandrel, ii) feed rate and iii) flow rate of the lubricant as process parameters. The process parameters are studied using RSM's Box Behnken design and a quadratic mathematical model was developed. The model developed by RSM is further used to optimize the process parameters using Genetic Algorithm.

\section{Experimental set up}

Flow forming is an advanced, hot and cold working process for manufacturing seamless tubes. The forming process was performed on a single roller flow forming lathe machine shown in Fig.1.

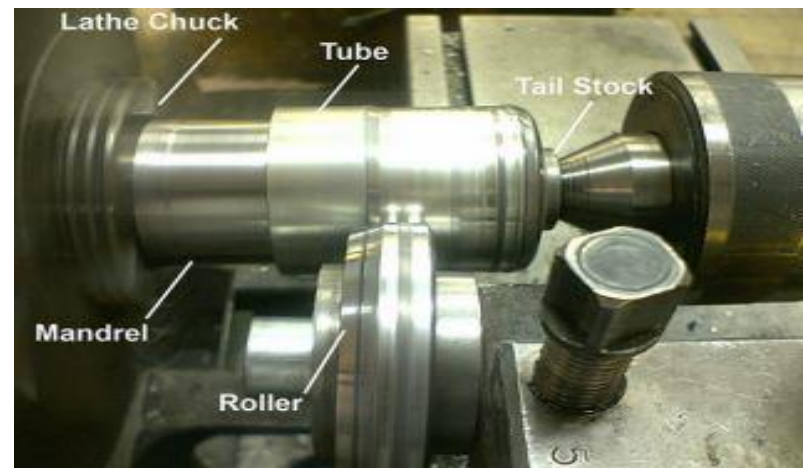

Fig. 1: Single Roller Flow Forming Lathe Machine [9].

The flow-forming roller travels along the workpiece axially with a feed rate, $\mathrm{V} \mathrm{mm} / \mathrm{min}$ with a depth of cut, Dc $\mathrm{mm}$ to reduce the wall thickness of the pre-form. The decrease in thickness of the 
preform increases the length of the tube because of volume constancy since the inside diameter is not changed. Surface finish is desired to produce the seamless tubes with a maximum percentage of elongation. The material used in the current study is aluminium alloy 8011. The composition of al 8011 is shown in Table 1

Table 1: Chemical Composition of Al 8011 Alloy

\begin{tabular}{llllllllll}
\hline Element & $\mathrm{Al}$ & $\mathrm{Fe}$ & $\mathrm{Si}$ & $\mathrm{Mn}$ & $\mathrm{Zn}$ & $\mathrm{Cu}$ & $\mathrm{Ti}$ & $\mathrm{Cr}$ & $\mathrm{Mg}$ \\
\hline Content $\%$ & 97.8 & 0.6 & 0.9 & 0.2 & 0.1 & 0.1 & 0.08 & 0.05 & 0.05 \\
\hline
\end{tabular}

The preform was manufactured by hot forged and is machined to fit the mandrel. The flow forming mandrel is made of tool steel. In the current study depth of cut is maintained constant ( $\mathrm{Dc}=0.2 \mathrm{~mm}$ ). The preform was manufactured as per Box Behnken design of experiments.

\section{Response surface methodology}

A statistical approach is a powerful tool to analyse the process parameters to get the desired optimal conditions. RSM is a collection of statistical and mathematical methods that are useful for modelling and analysing engineering problems. The process parameters that influence the surface roughness of the flow forming are the speed of the mandrel, feed rate, depth of cut, roller angles, type of lubricants used and flow rate of the lubricants etc. The process parameters considered in the study are the speed of the mandrel, feed rate and flow rate of the lubricant and are shown in Table 2.

Box Behnken design of RSM consisting of 17 experiments was conducted to develop the mathematical model for surface roughness attained by the flow formed tube. The results obtained for the conducted experiments obtained are shown in Table 3.

From the Table 4, the $\mathrm{P}$ value less than 0.05 , which shows that the model is significant. The mathematical model of the surface roughness obtained is given by equation (1).

Table 2: Input Process Parameters and Their Levels

\begin{tabular}{llll}
\hline Sl. No. & Input parameters & Low level & High level \\
\hline 1 & Feed $(\mathrm{mm} / \mathrm{min})$ & 30 & 90 \\
2 & Speed(rpm) & 200 & 300 \\
3 & Flow rate of lubricant $(1 / \mathrm{min})$ & 1.4 & 4.2 \\
\hline
\end{tabular}

Table 3: Experimental Results from Box Behnken Design

\begin{tabular}{|c|c|c|c|c|}
\hline & Factor 1 & Factor 2 & Factor 3 & Response \\
\hline Run & A:Feed & B:Speed & C:Flow rate & Surface roughness \\
\hline 1 & 60 & 250 & 2.8 & 1.8 \\
\hline 2 & 60 & 300 & 1.4 & 2.2 \\
\hline 3 & 30 & 300 & 2.8 & 2.1 \\
\hline 4 & 60 & 250 & 2.8 & 1.8 \\
\hline 5 & 90 & 300 & 2.8 & 4.6 \\
\hline 6 & 60 & 250 & 2.8 & 1.8 \\
\hline 7 & 60 & 200 & 4.2 & 2.3 \\
\hline 8 & 30 & 250 & 4.2 & 1.48 \\
\hline 9 & 90 & 250 & 4.2 & 4.4 \\
\hline 10 & 90 & 250 & 1.4 & 3.2 \\
\hline 11 & 60 & 300 & 4.2 & 2.32 \\
\hline 12 & 30 & 200 & 2.8 & 2.6 \\
\hline 13 & 30 & 250 & 1.4 & 1.38 \\
\hline 14 & 90 & 200 & 2.8 & 4.4 \\
\hline 15 & 60 & 250 & 2.8 & 1.8 \\
\hline 16 & 60 & 200 & 1.4 & 1.46 \\
\hline 17 & 60 & 250 & 2.8 & 1.8 \\
\hline
\end{tabular}

Table 4: ANOVA Table for Response Surface Model (Response: Surface Roughness, Ra $(\mu \mathrm{m})$ )

\begin{tabular}{|c|c|c|c|c|c|c|}
\hline Source & Sum of Squares & dof & Mean Square & F-value & p-value & \\
\hline Model & 18.03 & 9 & 2.00 & 78.31 & $<0.0001$ & significant \\
\hline A-Feed & 10.22 & 1 & 10.22 & 399.25 & $<0.0001$ & \\
\hline B-Speed & 0.0264 & 1 & 0.0264 & 1.03 & 0.3431 & \\
\hline C-Flow rate of lubricant & 0.6384 & 1 & 0.6384 & 24.95 & 0.0016 & \\
\hline $\mathrm{AB}$ & 0.1225 & 1 & 0.1225 & 4.79 & 0.0649 & \\
\hline $\mathrm{AC}$ & 0.3025 & 1 & 0.3025 & 11.82 & 0.0109 & \\
\hline $\mathrm{BC}$ & 0.1296 & 1 & 0.1296 & 5.07 & 0.0591 & \\
\hline $\mathrm{A}^{2}$ & 4.96 & 1 & 4.96 & 193.73 & $<0.0001$ & \\
\hline $\mathrm{B}^{2}$ & 1.23 & 1 & 1.23 & 47.99 & 0.0002 & \\
\hline $\mathrm{C}^{2}$ & 0.3069 & 1 & 0.3069 & 12.00 & 0.0105 & \\
\hline Residual & 0.1791 & 7 & 0.0256 & & & \\
\hline Lack of Fit & 0.1791 & 3 & 0.0597 & & & \\
\hline Pure Error & 0.0000 & 4 & 0.0000 & & & \\
\hline Cor Total & 18.21 & 16 & & & & \\
\hline
\end{tabular}




\begin{tabular}{ll}
\hline Surface roughness & $=$ \\
\hline+16.49750 & \\
-0.154500 & Feed \\
-0.106650 & Speed \\
+1.22321 & Flow rate \\
+0.000117 & Feed $*$ Speed \\
+0.006548 & Feed $*$ Flow rate \\
-0.002571 & Speed $*$ Flow rate \\
+0.001206 & Feed $^{2}$ \\
+0.000216 & Speed $^{2}$ \\
-0.137755 & Flow rate $^{2}$ \\
\hline
\end{tabular}

The equation 1 shows the quadratic mathematical model of surface roughness in terms of feed, speed and flow rate of coolant.

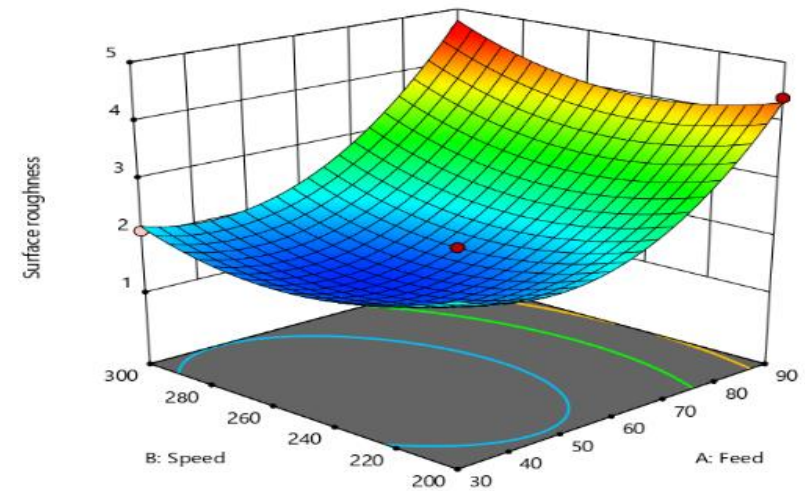

Fig. 2: Response Graph of Speed and Feed at Coolant Flow Rate of 3.08 L/Min.

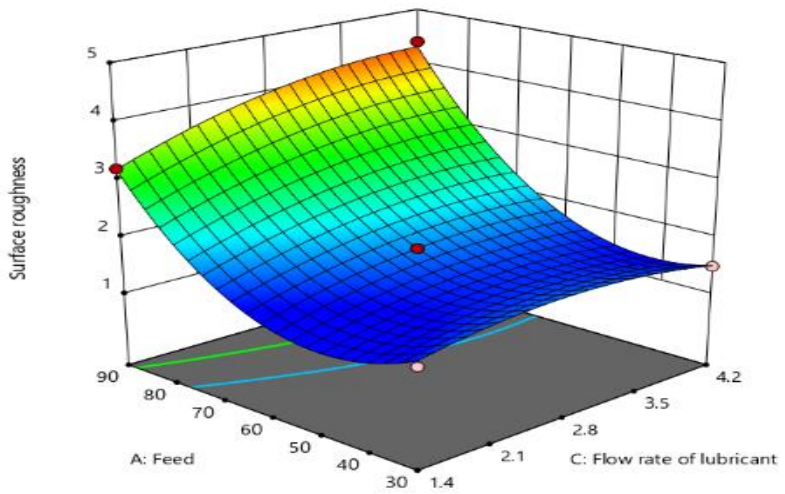

Fig. 3: Response Graph of Feed and Flow Rate of Lubricant at Speed 250 Rpm.

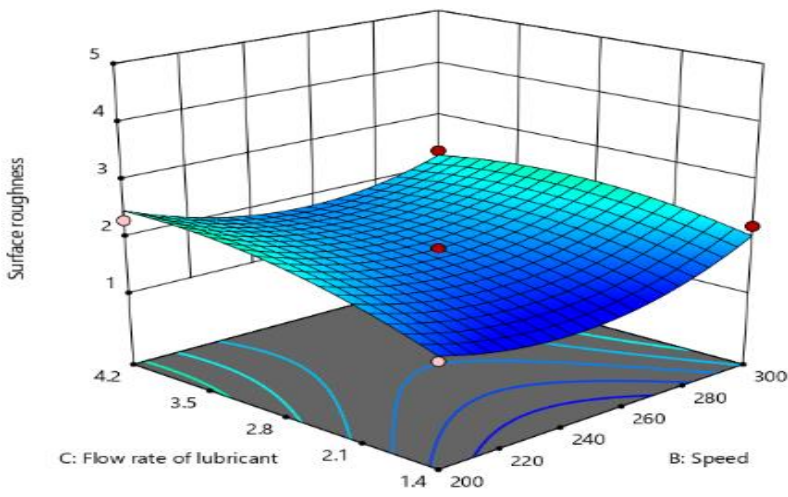

Fig. 4: Response Graph of Flow Rate of Lubricant and Speed at Feed 60 $\mathrm{Mm} / \mathrm{Min}$.

Fig. 2 gives the response surface graph for surface roughness at flowrate 3.08 1/min as speed and feed varies. Fig. 3 gives the re- sponse surface graph for surface roughness at speed $250 \mathrm{rpm}$ as feed and coolant flow rate varies. The good surface finish is obtained for a minimum amount of coolant. As this lubrication is sufficient to remove the heat generated during the forming.

Fig. 4 gives the response surface graph for the surface roughness at feed $=60 \mathrm{~mm} / \mathrm{min}$ as flow rate of coolant and speed varies. Higher feed and higher coolant levels maximizes the surface finish.

\section{Genetic algorithm}

Genetic algorithms (GA) are the heuristic search and optimization techniques that mimic the process of natural evaluation based on Darwin's theory. GA is based on the concept of "survival of the fittest". The basic working principle of GA is illustrated in flow chart Fig.5.

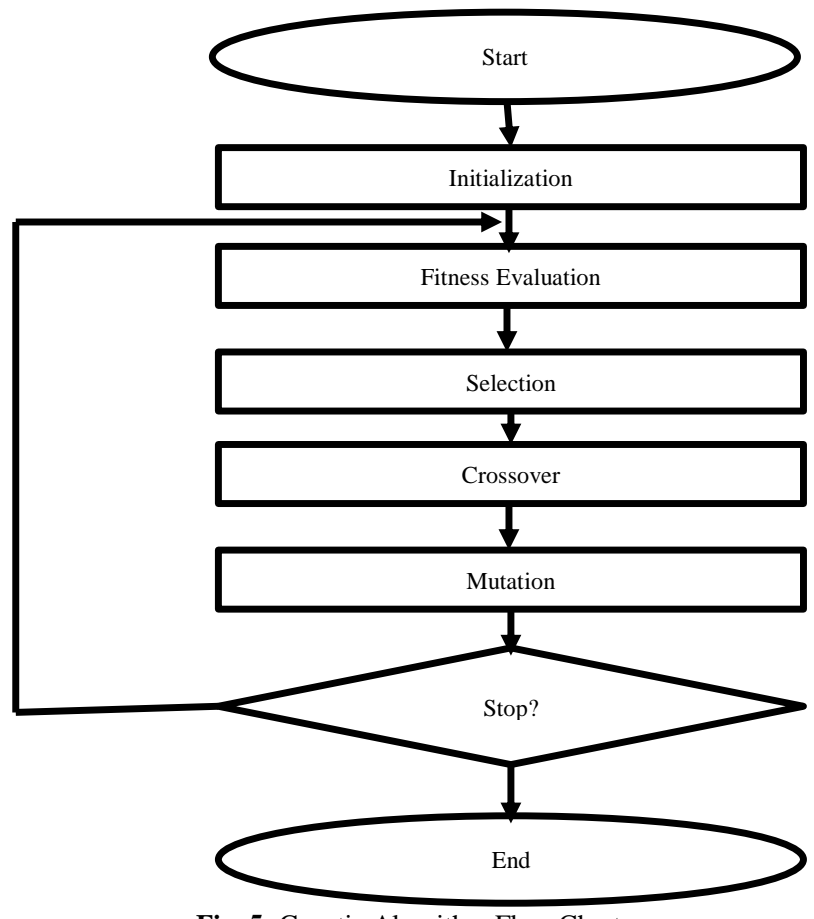

Fig. 5: Genetic Algorithm Flow Chart.

In the present work, the flow forming parameters were chosen to be the constraints and the surface roughness minimization of preformed was considered as objective function. The equation (1) obtained from response surface methodology is used as objective function, and the process parameters are optimized by using an evolutionary technique genetic algorithm. It is desired to produce seamless tubes of maximum percentage elongation ratio and good strength with excellent surface finish [2].

\subsection{Initialization}

The most common form of representing the input parameter as a chromosomes is a string of binary digits. Each bit in this string is a gene. The process of converting the original input parameters into the bit string is known as encoding.

The optimization model for current problem is formulated with parameters feed as $\mathrm{x}_{1}$, speed as $\mathrm{x}_{2}$ and flow rate of lubricant as $\mathrm{x}_{3}$ to minimize the surface roughness $\mathrm{f}(\mathrm{x})$.

As a first step, an initial population of 20 chromosomes with string length of 13 is generated randomly as shown in Table 5. The bit lengths chosen for $\mathrm{x}_{1}, \mathrm{x}_{2}$ and $\mathrm{x}_{3}$ are 4, 5 and 4 respectively Chromosome strings of individual input variables are decoded to the original variables using linear mapping rule [15] as shown in equation (2).

$\mathrm{x}_{\mathrm{i}}=\mathrm{x}_{\mathrm{i}}^{(\mathrm{L})}+\frac{\mathrm{x}_{\mathrm{i}}^{(\mathrm{U})}-\mathrm{x}_{\mathrm{i}}^{(\mathrm{L})}}{2^{\mathrm{l}}-1} \mathrm{DV}\left(\mathrm{S}_{\mathrm{i}}\right)$ 
In the above equation the variable $x_{i}$ is coded in a sub string $S_{i}$ of length $L_{i} \cdot x_{i}^{(U)}$ is the upper limit of the parameter $x_{i}$ and $x_{i}^{(L)}$ is the lower limit of the parameter $x_{i}$.

From Table 5, the first string (0001 001110011$)$ is decoded to values equal to $x_{1}=34, x_{2}=223$ and $x_{3}=2$ using eqn (2). Then the objective function is evaluated by using equation (1) and the value is 2.22. Tables 5, 6 and 7 exhibit the implementation of GA for minimization of surface roughness. Sample calculations are shown for one iteration of the algorithm.

\subsection{Fitness evolution}

The fitness function is a particular type of objective function that prescribes the optimality of a solution in the genetic algorithm so that, that particular chromosome may be ranked against all the other chromosomes.

The fitness final value of the first string using the transformation rule $\mathrm{F}(\mathrm{x})=1.0 /(1.0+2.22)$ is obtained as 0.31 . This fitness function value is used in the reproduction operation of GA. Similarly, other strings in the population are evaluated and fitness values are calculated. Table 5 shows the objective function value and the fitness value for all the 20 strings in the initial population.

\subsection{Selection}

The selection is a process of selecting two or more parents from the population for crossing based on the fitness. Chromosomes that are evaluated with higher values (Fitness) will most likely be selected to reproduce whereas those with low values will be discarded. The good strings in the population are to be selected to form the mating pool. The various selection methods generally used are i) roulette wheel, ii) random selection iii) rank selection and iv) tournament selection. In this work, roulette-wheel selection procedure is used to select the good strings. As a part of this procedure, average fitness [10] of the population is calculated by adding the fitness values of all strings and dividing the sum by the population size and the average fitness of the population $\overline{\mathrm{F}(\mathrm{x})}$ is obtained as 0.25100 for the first string. The expected count is subsequently calculated by dividing each fitness value with the average fitness $\left(\frac{\mathrm{F}(\mathrm{x})}{\overline{\mathrm{F}(\mathrm{x})}}\right)$. For the first string, the expected count is $(0.31 / 0.25100)=1.231$. Similarly, the expected count values are calculated for all other strings in the population and shown in Table 6 . Then, the probability of each string being copied in the mating pool can be computed dividing the expected count values with the population size.

Table 5: Initial Population with Fitness Values in GA

\begin{tabular}{lllllll}
\hline S. No & Chromosomes & x1 & x2 & x3 & Objective & Fitness \\
\hline 1 & 0001001110011 & 34 & 223 & 2 & 2.22 & 0.31 \\
2 & 0100110101110 & 46 & 289 & 4.2 & 2.00 & 0.33 \\
3 & 1000000111000 & 62 & 210 & 2.9 & 2.70 & 0.27 \\
4 & 1101001000110 & 82 & 213 & 2.5 & 3.73 & 0.21 \\
5 & 1111000100100 & 90 & 206 & 2.1 & 4.29 & 0.18 \\
6 & 1100100100001 & 78 & 258 & 1.6 & 2.84 & 0.26 \\
7 & 0000001100100 & 30 & 219 & 2.1 & 2.40 & 0.29 \\
8 & 1110111111000 & 86 & 300 & 2.9 & 4.81 & 0.17 \\
9 & 1011110001101 & 74 & 277 & 3.8 & 3.37 & 0.22 \\
10 & 1001000111111 & 66 & 210 & 4.2 & 3.05 & 0.24 \\
11 & 1110101011100 & 86 & 268 & 3.6 & 4.42 & 0.18 \\
12 & 0000110010000 & 30 & 281 & 1.4 & 2.11 & 0.32 \\
13 & 1111111001110 & 90 & 290 & 4 & 5.18 & 0.16 \\
14 & 1100000111011 & 78 & 210 & 3.4 & 3.79 & 0.20 \\
15 & 0000111101011 & 30 & 297 & 3.4 & 2.39 & 0.29 \\
16 & 0011000001110 & 42 & 200 & 4 & 2.65 & 0.27 \\
17 & 1010001110000 & 70 & 223 & 1.4 & 2.15 & 0.31 \\
18 & 1010010101111 & 70 & 232 & 4.2 & 3.01 & 0.24 \\
19 & 1100101101100 & 78 & 271 & 3.6 & 3.65 & 0.21 \\
20 & 0111001110000 & 58 & 223 & 1.4 & 1.73 & 0.36 \\
\hline
\end{tabular}

For instance, the probability of first string is $(1.231 / 20)=0.0618$ Similarly, the values of probability of selection for all the strings are calculated and cumulative probability is henceforward computed. The probabilities of selection are listed in Table 6. Next, random numbers between zero and one are generated in order to form the mating pool.

From Table 6, random number generated for the first string is 0.472 which means the tenth string from the population gets a copy in the mating pool, because that string occupies the probability interval $(0.45,0.5)$ as shown in the column of cumulative probability in the Table 6 . In a similar manner, other strings are selected according to the random numbers generated in Table 6 and the complete mating pool is formed. The mating pool is displayed in Table 6 . By adopting the reproduction operator, the inferior points have been automatically eliminated from further consideration. As a next step in the generation, the strings in the mating pool are used for the crossover operation[11].

\subsection{Crossover}

Crossover is a process of combining the bits of one chromosome with those of another. This is to create an off spring for the next generation that inherits traits of both parents. There are various types of crossovers such as i) one point crossover, ii) two point crossover, iii) multipoint crossover, iv) uniform crossover and v) athematic crossover.

In the crossover operation, two strings are selected at random and crossed at a random site. Since the mating pool contains strings at random, pairs of strings are picked up from top of the list as shown in Table 7.

Thus strings 1 and 6 participate in the first crossover operation. In this work, one point crossover is adopted with the probability, Pc $=0.5$ to check whether a crossover is desired or not. Single point crossover example is shown in Fig.6, where the crossover site is at $6^{\text {th }}$ bit. To perform crossover, a random number is generated with crossover probability $(\mathrm{Pc})$ of 0.5 . If the random number is less than Pc then the crossover operation is performed, otherwise the strings are directly placed in an intermediate population for subsequent genetic operation[11].

\subsection{Mutation}

Mutation is performed after crossover to prevent falling all solution in the population into a local optimum of solved problem [14] Mutation changes the new off spring by flipping bits from 1 to 0 or from 0 to 1 . Bit-wise mutation is performed with a probability, $\mathrm{Pm}=0.1$. A random number is generated with $\mathrm{Pm}$; if random number is less than Pm then the bit is altered form 1 to 0 or 0 to 1 depending on the bit value otherwise no action is taken. In the current study no mutation is performed.

The above procedure is continued until the maximum number of generations is completed. For better convergence of the present problem, the Genetic algorithm is run for 50 generations. GA narrows down the search space as the search progresses and the algorithm is converged to the objective function value of 1.345. The convergence graph is displayed in Fig.7 and the optimal values of the control factors are listed in Table 8. At these optimal control factors, an experiment is conducted and the surface roughness obtained is $1.352 \mu \mathrm{m}$.

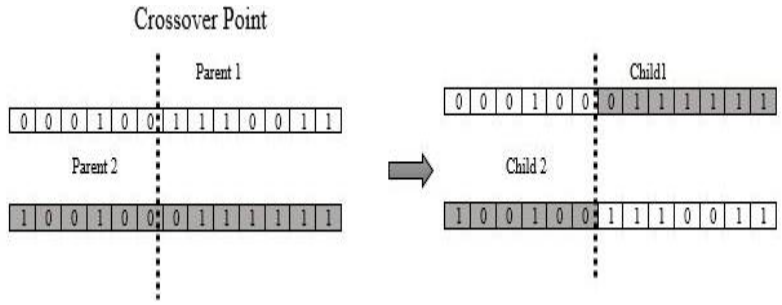

Fig. 6: Single or One Point Crossover of Chromosomes 
Table 6: Selection, Crossover and Mutation in GA

\begin{tabular}{|c|c|c|c|c|c|c|}
\hline Expected Count & $\begin{array}{l}\text { Probability of selec- } \\
\text { tion }\end{array}$ & $\begin{array}{l}\text { cumulative Proba- } \\
\text { bility }\end{array}$ & $\begin{array}{l}\text { Random Num- } \\
\text { ber }\end{array}$ & String Number & $\begin{array}{l}\text { True Count in } \\
\text { Mating Pool }\end{array}$ & Mating Pool Chromosomes \\
\hline 1.235 & 0.0618 & 0.0618 & 0.472 & 9 & 2 & 0111001110000 \\
\hline 1.315 & 0.0657 & 0.1275 & 0.165 & 3 & 3 & 0111001110000 \\
\hline 0.837 & 0.0418 & 0.2232 & 0.667 & 14 & 0 & 1010001110000 \\
\hline 0.717 & 0.0359 & 0.2590 & 0.456 & 10 & 0 & 1010001110000 \\
\hline 1.036 & 0.0518 & 0.3108 & 0.912 & 19 & 1 & 1010001110000 \\
\hline 1.155 & 0.0578 & 0.3686 & 0.923 & 19 & 2 & 0100110101110 \\
\hline 0.876 & 0.0438 & 0.4463 & 0.345 & 7 & 0 & 0100110101110 \\
\hline 0.956 & 0.0478 & 0.4941 & 0.201 & 4 & 0 & 0000001100100 \\
\hline 0.717 & 0.0359 & 0.5299 & 0.278 & 6 & 1 & 0000001100100 \\
\hline 1.275 & 0.0637 & 0.5937 & 0.288 & 6 & 1 & 0001001110011 \\
\hline 0.637 & 0.0319 & 0.6255 & 0.605 & 12 & 0 & 0001001110011 \\
\hline 0.797 & 0.0398 & 0.6654 & 0.625 & 13 & 0 & 1000000111000 \\
\hline 1.155 & 0.0578 & 0.7232 & 0.598 & 12 & 1 & 1100100100001 \\
\hline 1.076 & 0.0538 & 0.7769 & 0.192 & 4 & 1 & 1110101011100 \\
\hline 0.956 & 0.0478 & 0.8865 & 0.872 & 18 & 1 & 0000111101011 \\
\hline 0.837 & 0.0418 & 0.9283 & 0.589 & 12 & 0 & 0011000001110 \\
\hline 1.434 & 0.0717 & 1.0000 & 0.457 & 10 & 3 & 1010010101111 \\
\hline
\end{tabular}

Table 7: New Population and Their Corresponding Fitness

\begin{tabular}{|c|c|c|c|c|c|}
\hline New - Cross over Chromosomes ( New Population) & $\mathrm{X} 11$ & $\mathrm{X} 22$ & $\mathrm{X} 33$ & Objective & Fitness \\
\hline 0111000101110 & 48 & 256 & 3.44 & 2.12 & 0.32 \\
\hline 0111001101111 & 48 & 269 & 3.6 & 1.87 & 0.35 \\
\hline 0111001111100 & 48 & 273 & 3.12 & 1.86 & 0.35 \\
\hline 1011001110011 & 62 & 273 & 1.68 & 2.02 & 0.33 \\
\hline 1010110101110 & 58 & 334 & 3.44 & 2.35 & 0.30 \\
\hline 1000001100100 & 52 & 269 & 1.84 & 1.66 & 0.38 \\
\hline 0100111110000 & 38 & 350 & 1.2 & 1.55 & 0.39 \\
\hline 0100001110000 & 38 & 273 & 1.2 & 1.09 & 0.48 \\
\hline 0010001110000 & 32 & 273 & 1.2 & 1.24 & 0.45 \\
\hline 0000001100011 & 25 & 269 & 1.68 & 1.86 & 0.35 \\
\hline 0001001110100 & 28 & 273 & 1.84 & 1.72 & 0.37 \\
\hline 0000001110000 & 25 & 273 & 1.2 & 1.57 & 0.39 \\
\hline 1011000001110 & 62 & 250 & 3.44 & 3.00 & 0.25 \\
\hline 1100111101011 & 65 & 347 & 2.96 & 3.21 & 0.24 \\
\hline 1110101010000 & 72 & 318 & 1.2 & 2.63 & 0.28 \\
\hline 0000110010010 & 25 & 331 & 1.52 & 1.71 & 0.37 \\
\hline 0000000111000 & 25 & 260 & 2.48 & 2.20 & 0.31 \\
\hline 1010010110000 & 58 & 285 & 1.2 & 1.37 & 0.42 \\
\hline
\end{tabular}

Table 8: Optimal Values

\begin{tabular}{|c|c|c|c|c|c|}
\hline Variable & Feed $\left(\mathrm{x}_{1}\right)$ & Speed $\left(\mathrm{x}_{2}\right)$ & Flow rate of lubricant $\left(\mathrm{x}_{3}\right)$ & $\begin{array}{l}\text { Surface roughness }(\mu \mathrm{m}) \text { By } \\
\text { GA }\end{array}$ & $\begin{array}{l}\text { Surface roughness }(\mu \mathrm{m}) \\
\text { obtained from experiment }\end{array}$ \\
\hline Values & 40.52 & 254.53 & 1.82 & 1.345 & 1.352 \\
\hline
\end{tabular}

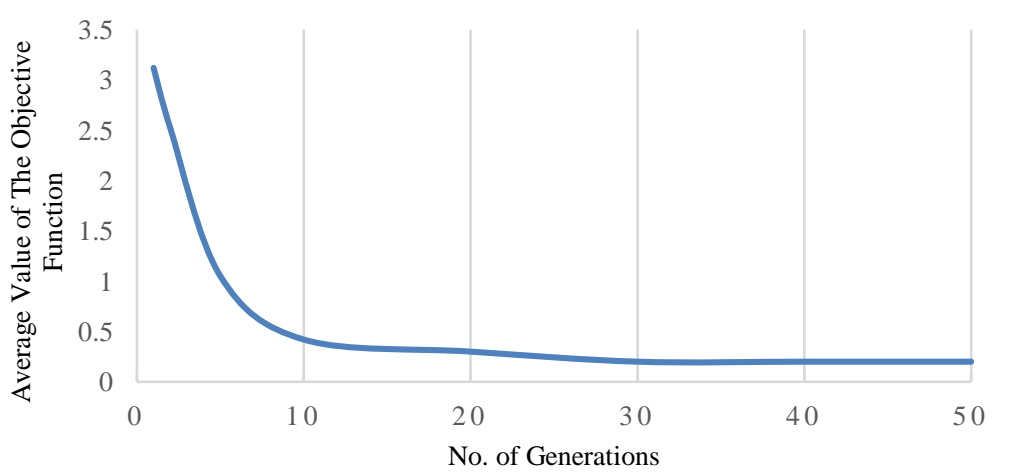

Fig. 7: Convergence Graph for Minimization of Surface Roughness.

\section{Conclusions}

In the current study, surface roughness of the flow forming of Al8014 preform is optimized with the set of process parameters by using an evolutionary technique Genetic Algorithm (GA). Box Behnken design of experiments is chosen to develop the mathe- matical model. A quadratic mathematical model developed by RSM is used as the input for the GA to optimize the surface roughness of the flow formed. The optimum process parameters obtained are feed at $40.52 \mathrm{~mm} / \mathrm{min}$, speed at $254.53 \mathrm{rpm}$ and flow rate of lubricant $1.82 \mathrm{lpm}$. At these optimum process parameters the surface roughness obtained is $1.345 \mu \mathrm{m}$ by GA. The surface roughness obtained by GA is in good agreement with the experimental value of $1.352 \mu \mathrm{m}$. 


\section{References}

[1] M. J. Davidson, K. Balasubramanian, and G. R. N. Tagore, "Experimental investigation on flow-forming of AA6061 alloy-A Taguchi approach," J. Mater. Process. Technol., vol. 200, no. 1-3, pp. 283 287, 2008. https://doi.org/10.1016/j.jmatprotec.2007.09.026.

[2] M. Joseph Davidson, K. Balasubramanian, and G. R. N. Tagore, "Surface roughness prediction of flow-formed AA6061 alloy by design of experiments," J. Mater. Process. Technol., vol. 202, no. 1-3, pp. 41-46, 2008. https://doi.org/10.1016/j.jmatprotec.2007.08.065.

[3] C. Paper and A. Kumar, "Processing of Seamless Tubes of Aluminum Alloy Aa2219 by Flow Forming," no. December, 2009.

[4] G. Venkateshwarlu, K. R. Kumar, and T. A. Janardhanreddy, "Experimental Study of Flow forming Process Parameters on Thickness variation of Aluminum Alloy AA6061 Tubes," vol. 2, no. 10, pp. 33-40, 2016

[5] M. Srinivasulu, M. Komaraiah, and C. S. K. P. Rao, "Experimental studies on the characteristics of AA6082 flow formed tubes," $J$. Mech. Eng. Res., vol. 4, no. October, pp. 192-198, 2012.

[6] X. Liu, C. Liu, L. Zhao, H. Huang, X. Zhao, and X. Sun, "The finite element method appling in the flow forming," CIS 2009 - 2009 Int. Conf. Comput. Intell. Secur, vol. 1, pp. 556-558, 2009. https://doi.org/10.1109/CIS.2009.202.

[7] H. R. Molladavoudi and F. Djavanroodi, "Experimental study of thickness reduction effects on mechanical properties and spinning accuracy of aluminum 7075-O, during flow forming," Int. J. Adv. Manuf. Technol., vol. 52, no. 9-12, pp. 949-957, 2011 https://doi.org/10.1007/s00170-010-2782-4.

[8] K. Deb, A. Pratap, S. Agarwal, and T. Meyarivan, "A fast and elitist multiobjective genetic algorithm: NSGA-II," IEEE Trans. Evol. Comput, vol. 6, no. 2, pp. 182-197, 2002. https://doi.org/10.1109/4235.996017.

[9] M. S. Mohebbi and A. Akbarzadeh, "Experimental study and FEM analysis of redundant strains in flow forming of tubes," J. Mater. Process. Technol., vol. 210, no. 2, pp. 389-395, 2010. https://doi.org/10.1016/j.jmatprotec.2009.09.028.

[10] K. Deb, Optimization for engineering design:Algorithms and examples. Prentice Hall of India, 2005

[11] O. F. Mechanical, "Ijmet (C I a E M E a Genetic Algorithm Approach To the Optimization of," pp. 459-470, 2012

[12] D. Marini, D. Cunningham, P. Xirouchakis, and J. R. Corney, "Flow forming: A review of research methodologies, prediction models and their applications," Int. J. Mech. Eng. Technol., vol. 7, no. 5, pp. 285-315, 2016.

[13] M. Sivanandini, S. S. Dhami, and B. S. Pabla, "Flow Forming Of Tubes-A Review," Int. J., vol. 3, no. 5, pp. 1-11, 2012.

[14] D. Venkatesan, K. Kannan, and R. Saravanan, "A genetic algorithm-based artificial neural network model for the optimization of machining processes," Neural Comput. Appl., vol. 18, no. 2, pp. 135-140, 2009. https://doi.org/10.1007/s00521-007-0166-y.

[15] G. H. Gowd and A. G. Krishna, "Empirical Modeling of Bead Geometry and Optimization in Laser Beam Welding," vol. 4, no. III, pp. 427-454, 2011. 